\title{
HEALTH PROMOTION IN CONNECTION TO THE HEALTH CARE STUDENTS
}

\author{
S. Kyuchukova*, P. Ivanova \\ Department Health Care, Medical Faculty, Trakia University, Stara Zagora, Bulgaria
}

\begin{abstract}
The activities of health promotion for the students in health care specialties is organized and managed by the teacher process. During the training communication skills are acquired. It is the time for preparing students for work in counseling and patient education, collecting and providing health information - promotive function in the process of care (1). We assumed that these opportunities could be used in our work with children deprived of parental care. We set a goal to explore experiences, attitudes and ideas about students' participation in health care in health promotion in the community of children and individuals. The study found that students are aware of the social importance of the knowledge acquired during the training and are convinced of the need to support adolescents to develop a responsible attitude towards their own health.
\end{abstract}

Key words: Participation students, Health education, children deprived of parental care, health behavior.

\section{INTRODUCTION}

The lack of healthy life habits and awareness in teenagers leads to poor nutrition, smoking, use of harmful substances and too early sex life (2). A healthy lifestyle, of course, depends on the economic, the social factors and the ecology.

Students from the Department 'Health care' of the Medical Faculty at the Thracian University Stara Zagora participate in the development and implementation of a project entitled "Formation of health knowledge and culture among young people in homes for children deprived of parental care". It used a method of projects as a method of learning through activities (3). The expected results related to the project activities are aimed at building a lasting interest and sustainable skills in the school-age children to inform themselves in topics related to living positive health life. This is accomplished through active interaction and influence among children, students, trainers, educators and teachers. Students unleashed activity by making multimedia presentations, visual and printed materials included in the

*Correspondence to: Kyuchukova Silviya, Trakia University, Medicine Facultacity, Department Health care, Bulgaria, Stara Zagora, Armeyska 9 street, tel.: +359 898636 514; e-mail: silviya.kyuchukova@trakia-uni.bg training groups for adolescents. They were interested in the teamwork, the ability to help others, building communication skills and shaping of the self. 'Group work helped to form in students skills for cooperation, tolerance, respect, communication, but also to defend the position, leadership and social activity" (4). The impact gained through visual models, color diagrams and sound activated adolescent for mental activity and raised the level of their knowledge and skills. As a result we achieved forming of a deliberately positive health behavior in children deprived of parental care.

\section{OBJECTIVE}

Research experience, attitudes, ideas about students of health care in the health promotion in the community and the individual.

\section{MATERIALS AND METHODS}

For the purpose of the study we have used the documentary method - literary analysis, an anonymous survey, which covers 54 students from the Medical Faculty of the Thracian University, Department Health Care (fourth and sixth semester of learning) and students in the specialty "Nurse". There was also an analysis based on face-to-face interview with teachers and students created. 


\section{RESULTS AND DISCUSSION}

According to the students the health promotion and prevention of socially significant diseases began during the training. All respondents 98\% are willing to participate in activities related to health promotion. According to 56\% of the students people do not pay enough attention to their health until there is a medical problem and only then tend to change their attitude.

Respondents who believe that man must be convinced of the connection between health behavior and health is $83 \%$. According to $42 \%$ of the students the information must be presented in an appropriate manner according to the cultural and age differences. Currently the schools are occupied by printed and verbal information technologies. According to 63\% of participants the use of presentations is much more appropriate because the background, the sound and the design have a strong impact on all the senses of the adolescents and that's why this is the most successful information technology method to improve the level of their knowledge and skills for formation of positive health behavior. Only $33 \%$ of the students consider printed and verbal information technologies for being successful methods for their perceptions and thinking and only $4 \%$ considered Role Playing Games as being appropriate method for these kinds of educational goals. (Figure 1).

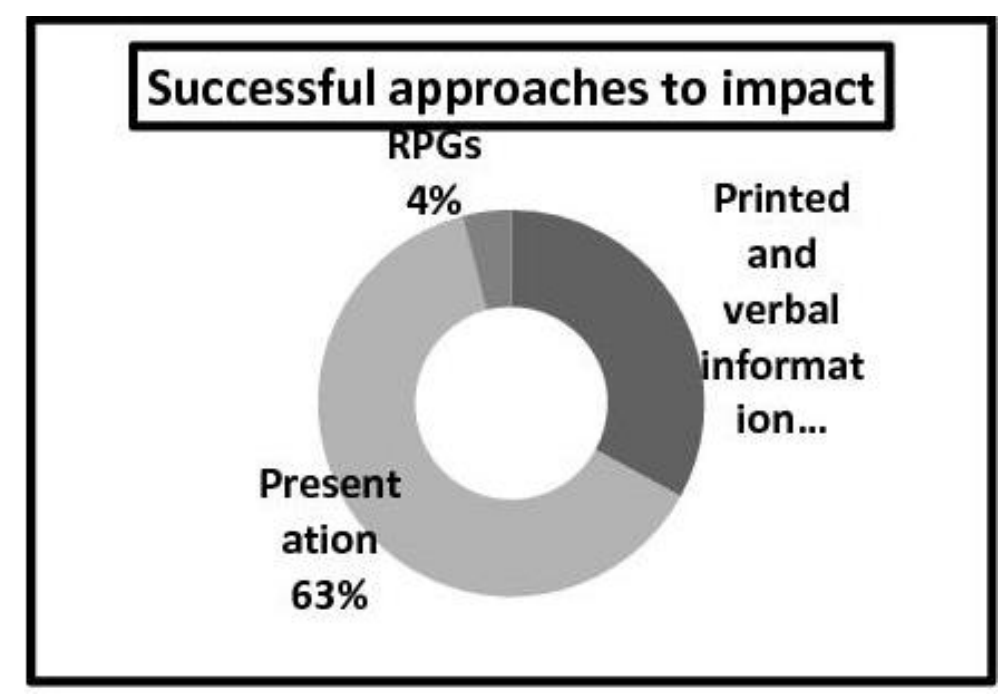

Figure 1. Methods impact on perceptions

The question that is finally important is "Do these promotion activities connected to health have an impact on the concerns of adolescents about health problem in general? "Almost all respondents- $91 \%$ believe that by training the young people are given a much greater clarity on the problems encountered in this age. Only 9\% of students did not answer. (Figure 2)

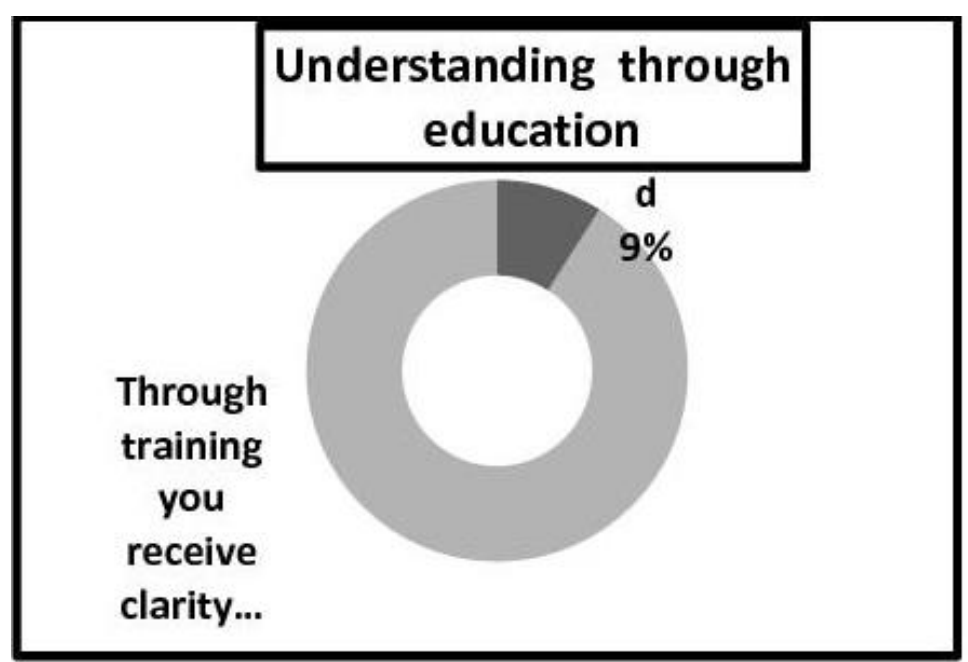

Figure 2. Impact on participants 
After being handled statistically the results of other interesting questions gave us the final result of the research and it was found that students considered the discipline of health promotion useful and important, especially for people at a young age because young people need to be well and properly informed about the possible health problems. Sharing of diverse experience and knowledge from their own individual life leads to building the capability to distinguish negative from positive health behavior.

\section{CONCLUSIONS}

All students are convinced of the need for assistance of the adolescents to develop a responsible attitude towards their own health.

The mode of transmission of knowledge and experience should motivate its accessibility, an enjoyable emotion and humanity in the relationship between students and adolescents should be aimed and achieved.

The promotion of lasting interest in adolescents in appropriate information associated with health problems builds motivation for leading a healthy life.

Students recognize the social importance of the knowledge acquired during their studies at the university.

\section{RECOMMENDATIONS}

The involvement of more students in projects to promote health which offer professional contacts and separate activities under the supervision or a teacher leads to their professional and personal development.

\section{REFERENCES}

1. DV № $15 / 18.02 .2011$

2. http :/ / nursing-bg.com

3. Yankulova - Tsvetkova, J. Modern aspects of psychology of education. Propeller, 2006

4. Andonova, A., The satisfaction of the students from the education in connection to the promotion of Health knowledge, 9 International Balkan education and science congress, 16-18.10.2014, Edirne, pp. 518520 